\title{
Attitudes Towards Occupy Central and Factors That Influence Attitudes
}

\author{
Yuwei Jiang ${ }^{1}$ \\ ${ }^{1}$ International Department, Liaoning Province Shiyan High School, Shenyang, China \\ Correspondence:Yuwei Jiang, International Department, Liaoning Province Shiyan High School, Shenyang, China.
}

Received: March 27, 2015

Accepted: April 10, 2015

Available online: April 22, 2015

doi:10.11114/ijsss.v3i3.787

URL: http://dx.doi.org/10.11114/ijsss.v3i3.787

\begin{abstract}
This paper quantitatively and qualitatively analyzes people's attitudes towards Occupy Central and what factors influenced their attitudes. The data was collected by using questionnaires sent out by investigators in Hong Kong, mainland China and through the Internet, using Qualtrics, provided by the Teachers College of Columbia University. At the beginning, information about Hong Kong Special Administrative Region (HKSAR) and Occupy Central is given, followed by an introduction of purpose and methodology. Then, data analysis, both quantitative and qualitative, is shown, followed by a discussion about the results of the analysis and conclusions.

The key research questions were about how people's attitudes towards Occupy Central were influenced by eleven factors: gender, age, occupation, residency, travel experience, whether they have children under the age of eighteen, their knowledge about Occupy Central, their accessibility to Occupy Central, the influence Occupy Central had on them, their ideas about a region's development and their ideas about a country's development. An analysis of statistical data, with tests of mean scores and t-tests, suggested some factors that influence people's attitude. People's occupations played a role in influencing their attitudes, especially between government officers and people from other sectors. How people were influenced significantly affected their attitudes with a more negative attitude related to negative influences. People's residency also influenced people's attitudes with people from the mainland China holding more negative attitudes towards Occupy Central than Hong Kong residents and with people from other places holding the most positive attitudes. The ideological difference in development of a region and a country also played an important role in influencing people's attitudes.
\end{abstract}

Keywords: Occupy Central, attitude, eleven factors, occupation, influence, residency, ideological difference, descriptive test, mean test, t-test

\section{Introduction}

In Hong Kong, a group of pro-democracy citizens occupied several central business districts, arguing for their universal suffrage rights in 2014. This event was called Occupy Central and it immediately caused controversy around the world. According to the report of News Magazine, a news program on Asia Television (ATV), the pro-democracy group was dissatisfied with the work of the Chief Executive of the Hong Kong Special Administrative Region (HKSAR), Leung Chun Ying, and the existing electoral system. They argued that the existing system only represented the benefits of the minority and ignored the equal rights of others (News Magazine, 2014). As for the media from mainland China, they reported that the behavior of Occupy Central groups was regarded by Chinese people as illegal and irrational and it largely influenced the economic and financial environment of Hong Kong (Zhang, 2014).

In order to evaluate the whole event, the attitudes from different groups are important. For this reason, we did a survey to find out people's attitudes towards Occupy Central. Since it seemed that the attitudes represented by various groups were different, we also wanted to know what factors had influenced people's attitudes towards this event.

\subsection{HKSAR}

The Sino-British Joint Declaration was signed on December 19, 1984, providing basic policies in Hong Kong. Hong Kong came back to People's Republic of China on July 1, 1997, which is also the date when the Basic Law of HKSAR came into effect.

Considering the political system in the HKSAR, the Basic Law proclaimed that the HKSAR shall come directly under the Central People's government of the People's Republic of China and enjoy a high degree of autonomy (National People's Congress, Article 12, 1990). The important leader of Hong Kong, the Chief Executive shall be selected by 
election or through consultations held locally and be appointed by the Central People's Government. The nomination shall be conducted by a broadly representative nominating committee and by democratic procedures (National People's Congress, Article 45, 1990). In Annex I, the Basic Law further demonstrated that the Election Committee shall be composed of 800 members, 200 members from each sector and the term of the office of the Election Committee is five years (National People's Congress, Annex I, 1990). The sectors are shown in the Table 1.

Table 1. The Sectors in Election Committee of HKSAR

Industrial, commercial and financial sectors

\begin{tabular}{l} 
The professions \\
\hline Labor, social services, religious and other sectors \\
\hline Members of the Legislative Council, representatives of district-based organizations, Hong Kong deputies to the \\
National People's Congress, and representatives of Hong Kong members of the National Committee of the \\
Chinese People's Political Consultative Conference
\end{tabular}

Source: National People's Congress, Annex I, 1990

The chief executive is elected for a term of five years and is allowed to be re-elected once (National People's Congress, Article 46, 1990). Today, Hong Kong's chief executive is Leung Chun Ying. He was elected as the chief executive on March 25, 2012 and was sworn into office on July 1 of the same year (Yang, 2012).

\subsection{Occupy Central}

Officially beginning from September 28, 2014, pro-democracy groups occupied several central business districts in Hong Kong, including Central, and Mong Kok, with tents, road blocks, and signs with slogans arguing for their universal suffrage rights. They believed that the existing electoral system was unequal and unfair. There were many signs in occupied districts with the slogan "I want real universal suffrage." The words clearly demonstrated their dissatisfaction with the present government and disbelief in the existing system.

In response to the Occupy Central groups' arguments, Leung claimed that he and his government had always respected the expression of individual ideas and the public were encouraged to use rational, peaceful and lawful approaches to express their ideas and to accept different views in society. He also promised that he and his government would follow the Basic Law and the relevant decisions of the National People's Congress Standing Committee (NPCSC) and strive to implement the election of the chief executive by universal suffrage in 2017 (China Daily, 2014). The Hong Kong government stated many times that Occupy Central was illegal and urged the groups to leave those occupied places.

However, few pro-democracy groups believed Leung's statements and refused to leave the occupied districts. On October 21, the Hong Kong government held a meeting with the representatives of students, who were actively involved in organizing the protests, to discuss issues related to Occupy Central. However, in a later interview, the student leaders claimed that the government had no sincerity in solving the problems and they would not leave the occupied places (Xia, 2014). Armed suppression by the police also failed to dispel Occupy Central groups (Fang, 2014).

However, there was also another group of people: anti-Occupy Central group. They argued that since pro-democracy groups occupied the central business districts, they had largely influenced the local economy and tourism and their behavior had no benefits for Hong Kong, but only harmful effects. They urged Occupy Central groups to stop their irrational behavior (Late News, 2014).

A survey started by the research organization of Hong Kong Commercial Daily revealed that over $98 \%$ of interviewees from the business community were against Occupy Central and, among them, 55.7\% of them strongly disagreed with the behavior of Occupy Central groups (SN182, 2014). Not only people from the business community participated in the anti-Occupy Central groups. The signature campaign demonstrating people's strong will to support police and against Occupy Central organized by Alliance for Peace and Democracy had collected over 1.83 million signatures through on-street vote stations and the Internet (China 24, 2014).

\subsection{Purpose of this Survey}

Different groups of people hold different attitudes towards Occupy Central. This event not only reveals the political conflicts between mainland China and Hong Kong, but also implies the ideological difference. Our purpose in doing this survey was to find out how different groups of people think about Occupy Central and what factors might influence their attitudes.

\section{Methodology}

This section outlines the participants and their basic information as well as the instruments, procedures, data collection 
methods, processing and analysis.

\subsection{Participants and their Basic Information}

There were 120 participants with different backgrounds who filled in the questionnaire during the data collection period and 11 participants (3 living in mainland China, 5 living in Hong Kong, 3 living in other places) took an interview after filling in the questionnaire.

\subsection{Instruments}

In order to measure the attitudes of people, we use both quantitative data from questionnaires and qualitative interviews as supplementary information.

We designed 16 questions in total to get the basic information of participants and to measure their attitudes and their ideas about items related to Occupy Central.

The first five questions asked about their basic information, including gender, age, occupation, whether they have children under the age of 18 , and their residency status. Then, three questions asked about participants' travel experience abroad, to mainland China, or to Hong Kong. The following four questions asked about their knowledge of Occupy Central, their access to Occupy Central, the approaches they employed to gain information about Occupy Central and the influence Occupy Central had on them. Then, there were three ranking questions asking participants to put items in order according to their importance. The first asked about the aspects of daily life they think are important; the second asked about aspects of a region's development; the third asked about aspects of a country's development. The last question was aimed at measuring participants' attitudes towards Occupy Central. All questions in the questionnaire except the three ranking questions and the one about occupation were Likert-scale questions.

After participants filled in the questionnaire, we asked for their ideas about taking an interview. The questions for interviews were raised based on their answers to the three ranking questions and their attitude indicated on the last question. The questions included: Why do you hold this attitude towards Occupy Central? Why do you think Occupy Central influences you in this way? Why do you think this item is most (or least) important for you?

\subsection{Changes Made on Questionnaires and Interview Prompts}

The questionnaire was carefully translated into Chinese when we did the survey in mainland China. We did our best to ensure the survey results would not be influenced by the translation.

Most of the items retained exactly the same meaning as the questionnaire for the Hong Kong survey. Some changes were made to the wording of some questionnaire items and interview prompts between the Hong Kong and mainland China data collection. Changes made to the mentioned items will be explained below.

After reorganizing the data from Hong Kong, we found that if we made 5 the number for most important items and 1 as for the least important in the three ranking questions, it would be more convenient for the data analysis process, so we made this change. All Hong Kong residents' answers were recorded in the same way. Thus, the survey result would not be influenced.

When doing the survey in Hong Kong, Q7 was about whether interviewees have been to mainland China. However, when our investigators came back to the mainland to do the survey, most interviewees were at present living in mainland China and they had obviously been to mainland China, so we changed the question into whether they had been to Hong Kong. The online version of the questionnaire included both questions since we might get answers from people who were then living outside China. This Q7 was aimed at finding out the influence of long-term travel experience to Hong Kong (for mainlanders and foreigners) or to mainland China (for Hong Kong residents and foreigners). This change would not influence the survey results since we still got information about their living experience in both Hong Kong and China for all participants.

As for the interview, we asked the questions mentioned above, but sometimes we also asked some questions in order to make the interviewees clarify their points. The questions were intended to get rid of misunderstandings and would not influence our analysis about the interview.

\subsection{Procedures}

The questionnaires were distributed to people by hand when the investigators were in Hong Kong and mainland China. We also used the Internet as an approach to send out the questionnaires.

In Hong Kong, the majority of people spoke English fluently and thus the language used in the questionnaire and the interview was English. The locations we sent out questionnaires in Hong Kong included North Point, Mong Kok, Central, and Kowloon. They were dispersed by hand and we randomly asked people walking by whether they would like to fill in the questionnaire. After getting permission, we introduced the purpose and contents of the questionnaire 
and then participants were required to fill it in by hand. After participants finished the questionnaire, a request for an interview was raised, and, after getting permission, we interviewed them according to their responses to the questionnaire. All responses were entered into Excel and Word manually later to make an electronic version of the data.

In mainland China, we translated the questionnaire into Chinese (Mandarin) and used Chinese to do the survey. The locations we sent out questionnaires included different places in northeast China: Liaoning Province Shiyan High School, Liaoning University, Tesco, an extracurricular class, a city government office and a petrochemical company. In Shiyan High School, we entered each classroom to announce the purpose of the survey and requested the students to complete the questionnaires. In other places, questionnaires were dispersed in the same way as we did in Hong Kong. The data were then translated, reorganized and entered into the same files.

On the Internet, we exported our questionnaires through Qualtrics, provided by the Teachers College of Columbia University. The language of the online questionnaire was English. Interviews were not requested through the online survey. The data was organized automatically by the software and edited manually to fit with our original data collection.

\subsection{Data Processing}

During the data analysis period, we chose 102 questionnaire responses to analyze. Eighteen questionnaire responses were eliminated due to problems such as incompleteness and unclear responses. The basic information of these 102 participants is shown in Table 2 .

Table 2. Basic Information of the 102 Participants

\begin{tabular}{|c|c|c|c|c|c|c|c|c|c|c|c|c|c|c|}
\hline \multicolumn{3}{|c|}{ Gender } & \multicolumn{6}{|c|}{ Age } & \multicolumn{2}{|c|}{ Children } & \multicolumn{3}{|c|}{ Residency } & \multirow{2}{*}{ Total } \\
\hline $\mathrm{F}$ & $\mathrm{M}$ & Other & $<18$ & $18-24$ & $25-34$ & $35-44$ & $45-54$ & $>55$ & Yes & No & $\mathrm{HK}$ & $\mathrm{MC}$ & Other & \\
\hline 44 & 56 & 2 & 38 & 18 & 18 & 16 & 11 & 1 & 77 & 25 & 9 & 85 & 8 & 102 \\
\hline
\end{tabular}

Note: F refers to Female, and M refers to Male. Children refer to Whether Participants Have Children Under the Age of Eighteen. HK refers to Hong Kong, MC refers to Mainland China.

In order to analyze questionnaire data, we assigned a value from -2 to 2 to attitude rating. Highly favorable statements about Occupy Central (Totally agree) were scored as 2, and others as 1 (Somewhat agree), 0 (Neutral), -1 (Somewhat disagree), and -2 (Totally disagree). The mean scores of participants' attitudes were then tested with regard to 11 different factors: their gender, age, occupation, residency, travel experience abroad or to mainland China (or Hong Kong), whether they have children under the age of eighteen, their knowledge about Occupy Central, their accessibility to Occupy Central, the influence Occupy Central had on them, their ideas about a region's development and their ideas about a country's development. T-tests were also conducted with regard to each factor. We analyzed the data using SPSS version 20 software.

The processing of other data related to our findings will be shown below.

\subsubsection{Occupation}

Participants were divided into five groups in terms of their occupation categories. The categories for different occupations were chosen and edited according to the Basic Law of Hong Kong. We changed the fourth category to government officers since we did not have participants from the fourth category indicated in the Basic Law. There was no category for students in The Basic Law but there were students participating in the survey, so we also added the fifth category for students. Details about occupation categories are shown in Table 3.

Table 3. Occupation Categories

\begin{tabular}{c|c}
\hline Code & Occupation Category \\
\hline 1 & Industrial, commercial and financial sectors \\
\hline 2 & The professions \\
\hline 3 & Labor, social services, religious and other sectors \\
\hline 4 & Government officers \\
\hline 5 & Students \\
\hline
\end{tabular}




\subsubsection{Influence Occupy Central had on Participants}

Participants were originally divided into five groups in the questionnaires according to their responses about how they were influenced by Occupy Central: Very negatively, Slightly negatively, No influence, Slightly Positively, and Very Positively. Their answers were then recoded and divided into three groups during data analysis: Negative influence, No influence, and Positive influence.

\subsubsection{Residency}

According to their questionnaire responses, participants were divided into three groups: Mainland China residents, Hong Kong residents, and residents from other places.

\subsubsection{Ideas about a region's development}

Participants were divided into four groups in terms of the responses indicated in the ranking questions about what they think is most important for a region's development and what is least important. These four groups were: Cohesion, Individual Voices, Leader's Ability, and Peaceful Environment.

\subsubsection{Ideas about a country's development}

Participants were divided into four groups in terms of the responses indicated in the ranking questions about what they think is most important for a country's development and what is least important. These four groups were: Economic Environment, Military Power, No turmoil, and Respect for Individual Rights.

\section{Findings}

Note: In the tables, * indicates significance at $10 \%$ level; ** indicates significance at $5 \%$ level; *** indicates significance at $1 \%$ level

\subsection{Questionnaires}

As mentioned above, in order to find what people's attitudes towards Occupy Central were and what factors might influence their attitudes, the mean scores of participants' attitudes were recorded and correlated with eleven different factors. Among all factors tested, we found that five of them showed significant influence on people's attitudes. Findings are presented below.

3.1.1 General attitude.

The distribution of participants grouped by their attitudes and the mean value of the scores of their attitudes was shown in Figure 1.

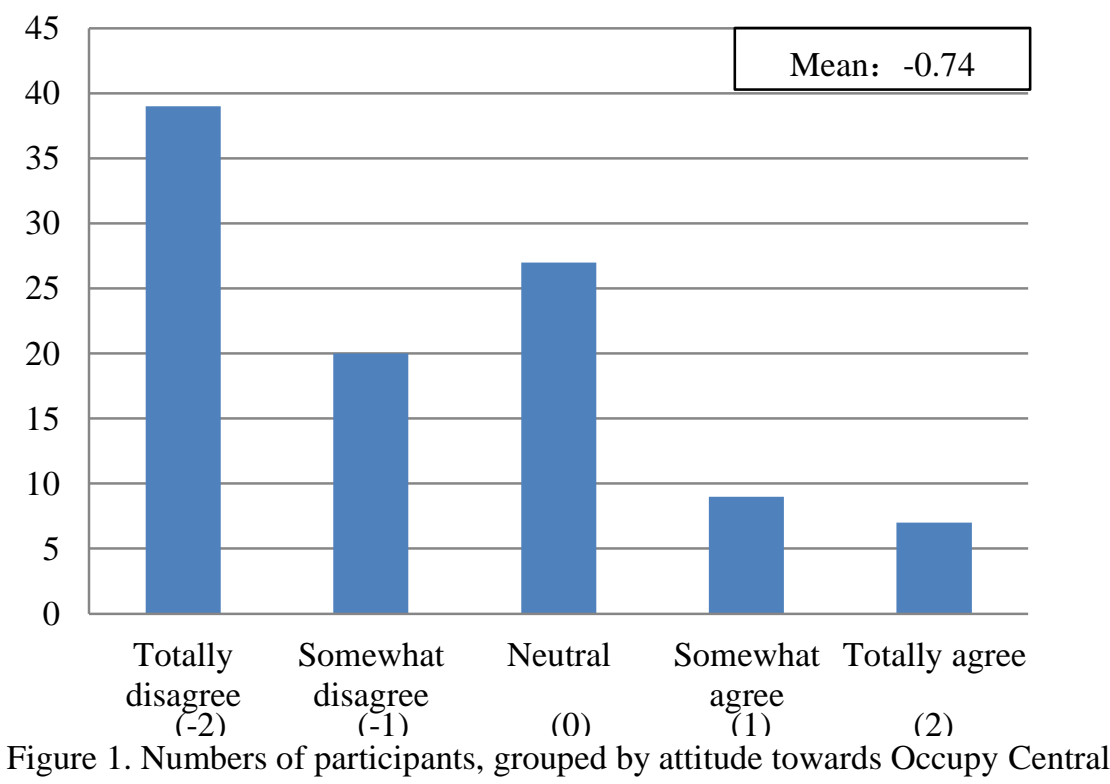

As we can see from Figure 1, more people held negative attitudes than those who held positive attitudes. The general attitude was negative. 


\subsubsection{Occupation}

The finding is that government officers held the most negative attitudes among all groups and professionals held the least negative attitudes. The difference in attitude between government officers and the professions, students and labor, social services, religious and other sectors was significant at the 5\% level. According to our research before doing the survey, people from the business community held very negative attitudes towards Occupy Central, (SN182, 2014) and we did find the attitudes of people from Industrial, commercial, and financial sectors were negative, but the difference in attitude between this community and others was not significant. The analysis of the attitude rating based on occupation categories are shown in Table 4.

Table 4. Average Attitude Rating Based on Occupation Categories

\begin{tabular}{|c|c|c|c|c|}
\hline $\begin{array}{l}\text { Occupation } \\
\text { categories }\end{array}$ & Mean & $\mathrm{N}$ & $\begin{array}{l}\text { Difference from category } 1 \\
\text { (t-value) }\end{array}$ & $\begin{array}{c}\text { Difference from category } 4 \\
\text { (t-value) }\end{array}$ \\
\hline 1 & -0.87 & 15 & $\begin{array}{l}-- \\
--\end{array}$ & $\begin{array}{c}0.419 \\
(1.059)\end{array}$ \\
\hline 2 & 0.00 & 7 & $\begin{array}{c}0.867 \\
(1.178)\end{array}$ & $\begin{array}{l}1.286^{* *} \\
(2.494)\end{array}$ \\
\hline 3 & -0.25 & 21 & $\begin{array}{c}0.617 \\
(0.913)\end{array}$ & $\begin{array}{l}1.036^{* *} \\
(3.181)\end{array}$ \\
\hline 4 & -1.29 & 55 & $\begin{array}{l}-0.419 \\
(-1.059)\end{array}$ & $\begin{array}{l}-- \\
--\end{array}$ \\
\hline 5 & -0.62 & 4 & $\begin{array}{c}0.248 \\
(0.660)\end{array}$ & $\begin{array}{c}0.668^{* *} \\
(2.485)\end{array}$ \\
\hline
\end{tabular}

3.1.3 Influence that Occupy Central had on participants

The average attitude rating based on how people were influenced by Occupy Central is shown in Table 5.

Table 5. Average Attitude Rating based on Influence Rating

\begin{tabular}{cccc}
\hline Influence & Mean & $\mathrm{N}$ & $\begin{array}{c}\text { Difference from Positive Influence } \\
\text { (t-value) }\end{array}$ \\
\hline Positive Influence & 1.17 & 32 & -- \\
\hline No influence & -0.66 & 58 & $1.822^{* * *}$ \\
\hline Negative Influence & -1.59 & 12 & $(5.216)$ \\
\hline
\end{tabular}

We can see that people who were positively influenced by Occupy Central held positive attitudes and those who were negatively influenced held negative attitudes. The difference in attitude between people who were positively influenced and those who were negatively influenced was significant at the $1 \%$ level.

\subsubsection{Residency}

From Table 6, we can see that Mainland China residents held the most negative attitudes while residents from other places held the most positive attitudes. Hong Kong residents held less negative attitudes than Mainland China residents and more negative attitudes than people from other places. Table 6 shows that the attitude difference between Hong Kong residents and Mainland China residents was significant at the $10 \%$ level and that between people from other places and Mainland China residents was significant at the 5\% level. 
Table 6. Average Attitude Rating based on Residency

\begin{tabular}{cccc}
\hline Residency & Mean & $\mathrm{N}$ & $\begin{array}{c}\text { Difference from Mainland China } \\
\text { (t-value) }\end{array}$ \\
\hline Mainland China & -0.93 & 85 & -- \\
\hline Hong Kong & -0.11 & 9 & $-0.818^{*}$ \\
Other & 0.63 & 8 & $(-2.005)$ \\
\hline
\end{tabular}

3.1.5 Ideas about a region's development

The data analysis of participants' attitude rating based on their ideas about a region's development is shown in Table 7 . The table grouped participants according to items that are the least important to them.

Table 7. Average Attitude Rating, Grouped by Items Participants Regarded as least Important for a Region 'S Development

\begin{tabular}{cccc}
\hline $\begin{array}{c}\text { Ideas about a Region's Development } \\
\text { (Least Important) }\end{array}$ & Mean & $\mathrm{N}$ & $\begin{array}{c}\text { Difference from Individual Voices } \\
\text { (t-value) }\end{array}$ \\
\hline Cohesion & -0.17 & 23 & $\begin{array}{c}1.026^{* * *} \\
(3.225)\end{array}$ \\
\hline Individual Voices & -1.20 & 50 & -- \\
\hline Leader's Ability & -0.36 & 14 & $0.843^{* *}$ \\
\hline Peaceful Environment & -0.40 & 15 & $0.800^{* *}$ \\
\hline
\end{tabular}

From Table 7, we can see that people who considered "Cohesion" to be the least important factor for a region's development held the most positive attitude and those who considered "Individual Voices" to be the least important held the most negative attitude, and we can see that the significance of this difference was below the $1 \%$ level. Table 7 also shows that the attitudes of participants who least valued "Leader's Ability" or "Peaceful Environment" were significantly more positive than those who ranked "Individual Voices" as least important.

3.1.6 Ideas about a Country's Development

The data analysis of participants' attitude rating based on their ideas about a country's development is shown in Table 8 . The Table grouped participants according to items that are the most important to them.

Table 8. Average attitude rating, grouped by items participants regarded as most important for a country's development

\begin{tabular}{cccc}
\hline $\begin{array}{c}\text { Ideas about a Country's Development } \\
\text { (Most Important) }\end{array}$ & Mean & $\mathrm{N}$ & $\begin{array}{c}\text { Difference from Respect for Individual Rights } \\
\text { (t-value) }\end{array}$ \\
\hline Economic Environment & -0.97 & 31 & $\begin{array}{c}1.178^{* * *} \\
(3.499)\end{array}$ \\
\hline Military Power & -0.61 & 23 & $\begin{array}{c}0.819^{*} \\
(1.787)\end{array}$ \\
\hline No Turmoil & -1.21 & 29 & $\begin{array}{c}1.417^{* * *} \\
(4.074)\end{array}$ \\
\hline Respect for Individual Rights & 0.21 & 19 & $\begin{array}{c}-- \\
--\end{array}$ \\
\hline $\begin{array}{l}\text { The finding is that people who put "Respect for Individual Rights" in the most important place for a country's } \\
\text { development held the most positive attitude, while people who put "No Turmoil” in the most important place held the }\end{array}$
\end{tabular}


most negative attitude. The significance of this difference was below the $1 \%$ level, as Table 8 shows. The table also showed that people who regarded "Economic Environment" as the most important factor held more negative attitudes than those who regarded "Respect for Individual Rights" as the most important. This attitude difference was also significant at $1 \%$ level. The attitude difference between the "Military Power" group and the "Respect for Individual Rights" group was significant at 10\% level, with the "Military Power" group holding more negative attitudes.

\subsection{Interview}

We were doing a survey related to people's attitudes towards Occupy Central and this issue was quite subjective, so we did in-person interviews as a supplementary measure. The main focus of our interviews was still what people's attitudes towards Occupy Central were and what factors might influence their attitudes.

\subsubsection{Influence Occupy Central had on them}

Among the 11 interviews, 6 interviewees' responses indicated the existence of a relationship between people's attitudes and how they think they were influenced. When asked about the reason why they hold negative attitudes towards Occupy Central, these participants mentioned the negative influence Occupy Central had on them and society. Their attitudes and responses are shown in Table 9.

Table 9. People's Attitudes towards Occupy Central and Responses Regarding to Its Influence on Them

\begin{tabular}{crc}
\hline Interviewee & Reason(Participants' responses) & Attitudes \\
\hline A & They can offer their opinions but cannot influence others. & Totally Disagree \\
\hline C & Because it influences our lives, and brings us inconvenience. & Somewhat Disagree \\
\hline D & ...not useful at all. They just influence others. They choose the wrong way... & Disagree \\
\hline E & ..., but they choose a bad approach. It influences economy. & Somewhat Disagree \\
\hline G & It influences economy. It influences the general environment of the country. & Totally Disagree \\
\hline I & TOTALLY DISAGREE. It influences us so much. & Totally Disagree \\
\hline
\end{tabular}

\subsubsection{Occupation}

Though in the quantitative analysis, we did not find whether participants belong to Industrial, commercial, and financial sectors or not has influence on their attitudes, from the interview responses, five in this category out of eleven interviewees demonstrated negative attitudes and thought Occupy Central had a negative influence on them and society. Though we cannot conclude that Occupy Central only has a negative influence on industry, commerce and finance, we still see that it does influence the benefits of some people who belong to this category and thus influenced their attitudes towards Occupy Central.

\section{Discussion}

The statistical analysis suggested that there was a relationship between how people were influenced and how people thought about Occupy Central. If they were negatively influenced, they tended to hold more negative attitudes. This result is not really beyond expectation. Actually it would be surprising if a person was hurt by Occupy Central but still supported it. Nobody would want his or her benefits being affected negatively. In most situations, people look for ways to maximize their benefits. If they thought Occupy Central was the way to maximize their benefits, then they would probably think they were positively influenced and thus hold more positive attitudes and if people hold negative attitudes towards Occupy Central, then it was probably because they thought their benefits were, in some way, negatively affected by this political campaign. This survey suggests that Occupy Central is a conflict of different approaches to maximize people's benefits. How people thought their benefits were influenced by Occupy Central seemed to be the key factor that would influence their attitudes towards it.

The findings also reveal other factors that might play an important role in affecting people's attitudes: people's ideas about a region's or a country's development. One speculation about why the issues they regarded as the most or least important for a region's or a country's development would influence their attitudes towards Occupy Central is that people develop their views about these issues based on how these issues would influence the maximization of their benefits. In other words, people might think one issue as the most important for a region or a country because a place with this issue can help them gain more benefits and think one as the least important because it has nothing to do with their benefits or even hurts their benefits. In the case of our survey, people regard "No Turmoil" as the most important probably because a peaceful environment without interruption would help them maximize their benefits. Thus, when asked about Occupy Central, these people would probably care more about the fact that Occupy Central hurts the peaceful environment, which they regard as the most important for a country's development or in some way as the most 
important for themselves, and thus would hold more negative attitudes. The test results supported the speculation. These ideological differences suggested by the findings could be interpreted as people's different ideas about how to maximize their benefits.

From the data analysis, residency was also a factor that influenced people's attitudes. One speculation about it is that people who live in different places would be in different economic environments and this difference in economic environments would influence their ways of thinking. Specifically, people in different economic environments would choose different ways to maximize their benefits, so they would think differently about to what extent things like "Cohesion" are important for a region. Thus they would feel differently about how the events had influenced things like "Cohesion" which are related to the maximization of their benefits.

The survey suggested that participants who lived in mainland China tended to have generally more negative attitudes than participants who lived in Hong Kong. According to the speculation, people in mainland China would have a different idea from people in Hong Kong about a region's development. The test designed for it supports the speculation. The result is shown in Table 10 .

Table 10. Ideological Difference between Hong Kong and Mainland China.

\begin{tabular}{ccccc}
\hline Residency & $\begin{array}{c}\text { Mean } \\
\text { (Cohesion) }\end{array}$ & $\begin{array}{c}\text { Difference from Hong Kong } \\
\text { (t-value) }\end{array}$ & $\begin{array}{c}\text { Mean } \\
\text { (Individual Voices) }\end{array}$ & $\begin{array}{c}\text { Difference from Hong Kong } \\
\text { (t-value) }\end{array}$ \\
\hline Hong Kong & 1.11 & -- & 3 & -- \\
\hline $\begin{array}{c}\text { Mainland } \\
\text { China }\end{array}$ & 2.68 & -- & 1.75 & -- \\
\hline
\end{tabular}

As the table represents, Hong Kong residents value "Individual Voices" more than the mainlanders, while mainlanders value "Cohesion" more than Hong Kong residents.

As predicted, different economic environments seem to produce ideological differences. In mainland China, even though the government gradually encourages the establishment of private companies, State-owned enterprises still comprise the largest part of the country's economy. A socialist market economic system dominates. Yet, in Hong Kong, The Basic Law has ensured a high degree of autonomy. A capitalist economic system thrives. A socialist market requires the sharing of social profits. In such an environment, people need to work together to maximize the social profits in order to maximize their own benefits. In this way, normal people might tend to believe that a country should develop as a whole in order to maximize benefits. "Cohesion" seems to be more important. On the other hand, a capitalist system requires the protection of individual possessions. People need to express their own ideas in order to protect themselves in a relatively more free market. Thus, they are inclined to believe that only if their own voices could be heard, would their benefits be maximized. When this ideological difference appears, people would judge Occupy Central differently, probably because they would think differently about how Occupy Central had influenced the maximization of their benefits.

Occupation was also a factor that might influence people's attitudes. The speculation about this factor is still that occupation influences how people think their benefits would be influenced by Occupy Central. The analysis suggested that government officers were the group that held more negative attitudes. The government officers held more negative attitudes, probably because they were among the group that was protested against by Occupy Central groups. It was easier for them to think they were negatively influenced by Occupy Central: their workload might increase, or their safety might even be threatened. Even if they were not in the departments that were directly targeted, the information surrounding them would mostly be about how Occupy Central had caused inconvenience to them. The situation above would probably be the reason why they tended to believe Occupy Central had influenced them negatively and thus be the reason why they held negative attitudes towards it.

\section{Conclusion}

Occupy Central revealed many conflicts: the conflict between Occupy Central groups and anti-Occupy Central groups, the conflict between the existing policy and the change that pro-democracy people wanted to make, and even the conflict between Hong Kong and mainland China. There might be many causes for conflicts. This survey suggested that ideological difference generated by different interest groups about how to maximize their benefits is one of them.

In the findings, Occupy Central's influence on people is the most significant factor that might have an effect on people's attitudes towards this event: Negative influences lead to negative attitudes, while positive influences lead to positive attitudes. The findings suggest that many people hold negative attitudes towards Occupy Central mainly because they think they were negatively influenced. Thus, it is not unreasonable to make the assumption that if the behavior of Occupy Central groups had not negatively influenced those people, those people would probably have not held negative 
attitudes towards Occupy Central. In this way, it would probably be easier for Occupy Central groups to realize their goals since the number of people in anti-Occupy Central groups which prevented Occupy Central groups from achieving their goals might have been much lower. This means that in order to achieve a goal, people not only need to make their goal noticed by other people; in fact, it is more important to think about a way to make other people notice the goal in a positive way.

In the case of Occupy Central, the goal of the pro-democracy group is to realize universal suffrage so that they could make their voice heard and argue for their own benefits. In the interview, many people implied that they accept this idea and even advocate this idea. What made them hold negative attitudes is that Occupy Central groups influenced their lives and economy negatively. Thus, if they had organized the campaign in a more proper way that had less negative influences, they might have gotten more supporters. However, if there had been less influences, other people might not have been able to notice their goals. It seemed that Occupy Central groups had to produce some negative effects on society in order to make others notice them. Then, a vicious cycle was begun. Negative effects, though they attract attention, take away supporters; the protesting group cannot achieve their goals and thus produce more negative influences to gain more notice.

It seems that a solution is needed to break the cycle. How to attract attention in a more proper way might be the key point that would allow us to break the cycle and relieve the conflict between Occupy Central groups and anti-Occupy Central groups. The government is a key factor in the solution. Suppression is not a good solution. It would only make the protesting group feel that they need more attention to make the change happen and more negative influences to make themselves noticed. Only by leading the protesting groups in a positive way can the conflict be reduced successfully. For example, the government could provide specific places in the city for people to make their voices heard so that the protesting groups do not need to block the central business areas for attention.

However, even if the protesting groups have a proper way to pursue their goal, this is not enough. The conflict between Occupy Central groups and anti-Occupy Central groups could be mediated, but the more important problem is the conflict between the existing system and the change that people want to make. It is dangerous and ineffective if we just let these conflicts exist since it would make the development of the region or the country frequently lead to quarrels and if the intense quarrels erupt at the same time, it would be horrible for the region or the country, so we need to understand the conflict and then get rid of it. The findings suggest that ideological differences are the reasons why there are conflicts: different people have different ideas about how to maximize their benefits and thus they have different ideas about a region's or a country's development. These ideological differences can appear as conflicts in a political way.

The key problem is how to accommodate different ideas in one government and avoid conflicts: whether the government should make compromises that allow each group to gain slight benefits and be satisfied with a merging of ideas. In fact, the balance of the distribution of benefits is important to keep society prosperous and away from conflicts, but it is hard to achieve perfect balance. In other words, it is impossible to let all groups gain their benefits simultaneously. Also, it is impossible to let everyone be satisfied because the ideological differences have been proved to exist: there is always a possibility that some people disagree with the existing situation. Thus, seeking perfect compromises that could avoid conflicts and satisfy everyone is too idealized; sometimes compromises would even make things worse. The conflicts cause problems but they are inevitable. Therefore, what the government can do is accommodate the differences and conflicts and make compromises that allow most groups to be satisfied and minimize other groups' loss of benefits. Otherwise, the government needs to overcome the ideological differences, which is almost impossible.

The findings suggest that the ideological differences exist between places with different economic environments. In different economic environments, people develop different ideas about how to maximize their benefits. Thus, there are conflicts between such places. In the case of Occupy Central, the difference exists between mainland China and Hong Kong and thus the conflicts exist between them. However, actually the economic environment in China is changing, especially in the coastal areas. Along with it, people's ideas are also changing. Yet this does not mean that China could finish the impossible task to overcome the ideological difference. The extent to which the change happened is not enough to make the difference disappear. Even if the gradual change could make mainland China not too different from today's Hong Kong, Hong Kong might gradually change to a different situation as well. Therefore, what China could do is accept difference and minimize the loss brought by the difference.

The shared goal of human beings to pursue benefits was split into different parts by the different approaches that are employed. The conflicts thus appear and some appear inevitably. What we can do is mediate the conflicts that can be mediated, avoid making the conflicts produce too many losses and accept other conflicts as inevitable elements of society. 


\section{Acknowledgement}

I would like to express my sincere gratitude to my teacher, Steven Cumberworth, who gave me the greatest help with his guidance and patience through the whole survey.

Also, I would like to thank my teacher, Austin Dwyer, for proofreading and useful suggestions, and my friends, Guoyu Zhu, Yuchen Liu, and Luyuan Zhao, for conducting questionnaires.

And finally, to all interviewees, who chose to accept and to fill in the questionnaires.

\section{Reference}

China daily. (September 28, 2014). HK gov't opposes unlawful actions by 'Occupy Central'. Retrieved from: http://www.chinadaily.com.cn/china/2014-09/28/content_18677923.htm

China 24 (November 4, 2014). Beijing: China Central Television.

Fang, H. (September 28, 2014).Occupy Central- Hong Kong Police Used Tear Gas. Next Magazine. Retrieved from: http://www.nextmag.com.tw/breaking-news/news/20140928/8610967

Late News (November 8, 2014). Hong Kong: ATV.

National People's Congress (1990). THE BASIC LAW OF THE HONG KONG SPECIAL ADMINISTRATIVE REGION OF THE PEOPLE'S REPUBLIC OF CHINA. Beijing, People's Republic of China

News Magazine. (November 8, 2014). Hong Kong: ATV

SN182 (November 3, 2014). Hong Kong survey reveals that over 98\% interviewed people from commercial sector were against Occupy Central]. China: SINA Corporation. Retrieved from: http://news.sina.com.cn/c/2014-11-03/161431087651.shtml

Xia, X. (October 22, 2014). Hong Kong Government Negotiated with Student Protestors-No Agreement achieved. Retrieved from: http://www.guancha.cn/local/2014_10_22_278549.shtml

Yang, F. (July 1, 2012). Profile: Leung Chun-ying, new chief executive of HKSAR. Retrieved from: http://www.gov.cn/english/2012-07/01/content_2174599.htm

Zhang, P. (October 5, 2014). Chinese public voice opposition against HK Occupy Central. Beijing: China Central Television. Retrieved from: http://english.cntv.cn/2014/10/05/ARTI1412462657644540.shtml

\section{Questionnaire}

\section{Appendix}

Linda's Survey

Q1 Gender

O Male $\bigcirc$ Female $\quad$ Other

Q2 Age

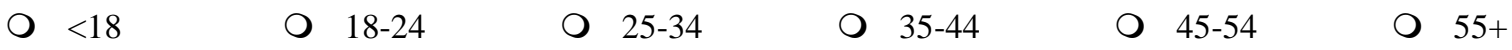

Q3 What is your occupation? (Field and Title) 
Q4 Do you have children under the age of 18 ?

O Yes

O No

Q5 Where do you live?
O Hong Kong
O Mainland China
O Other

Q6 Have you ever been abroad (Outside of China and Hong Kong)? If so, where and how long?
O Yes
O No

Q7 Have you ever been to Mainland China? If so, where and how long?

O Yes

O No

Q8 How much do you know about Occupy Central?

Much less than average

O Less than average

O Average

O More than average

O Much more than average

Q9 Are there any Occupy Central groups near your working place or living place?
O Yes
O No

Q10 Where do you get information about Occupy Central? (Check all that apply)

Dewspaper

口 Television

a Experience

Word of Mouth (Talking with others)

Internet

- Social Media

O Other (please specify)

Q11 How does Occupy Central influence you?
O Very negatively
O Slightly negatively
O No influence
O Slightly positively
O Very positively

Q12 Please put the following in order based on how important they are to you (1= Most Important; 5= Least Important)

$\begin{array}{ll} & \text { International issues } \\ & \text { Living conditions } \\ \text { Satisfactory income } \\ \text { Scientific breakthrough } \\ \text { Social welfare }\end{array}$

Q13 What do you think matters most for a region's development? Please put the following in order (1= Most important; 
$5=$ Least Important)

\begin{tabular}{l} 
Cohesion \\
\hline Individual voices \\
Leaders' ability \\
Peaceful environment \\
Other (Please specify)
\end{tabular}

Q14 Which aspect of a country do you think is the most important? Please put the following in order based on how important they are to you ( $1=$ Most Important; $5=$ Least Important $)$

Economic development

Military power

No turmoil

Respect for individual rights

Other (Please specify)

Q15 How much do you agree with the Occupy Central movement?

O Totally disagree $\bigcirc$ Somewhat disagree $\bigcirc$ Neutral $\bigcirc$ Somewhat agree $\bigcirc$ Totally agree

\section{(c) EY}

This work is licensed under a Creative Commons Attribution 3.0 License. 